\title{
IMPOTENCY ON RISE AMONG YOUNG MALE POPULATION
}

\author{
P. K. Dash ${ }^{1}$
}

\section{HOW TO CITE THIS ARTICLE:}

P. K. Dash. "Impotency on Rise among Young Male Population". Journal of Evolution of Medical and Dental Sciences 2015; Vol. 4, Issue 87, October 29; Page: 15144-15146, DOI: 10.14260/jemds/2015/2151

ABSTRACT: It may be defined as inability to perform sexual activity. Previously it was thought to be purely a psychological problem. Because of recent developments and better understanding of male sexual health, impotency or Erectile dysfunction (E.D.) is now considered to be medical problem also.

KEYWORDS: E.D. Erectile dysfunction or impotence-Erection problem of penis, Pornographyindecent literature or picture (Blue Film).

INTRODUCTION: Impotency or Erectile Dysfunction (E.D.) is defined as persistent inability to attain and maintain an erection good enough for satisfactory sexual activity. Impotency is derived from a Latin word 'Impotentia coeundi' meaning inability to insert penis into vagina. Some years back E.D. was considered to be a psychological problem only, but with increased understanding of male sexual health, quite number of cases are now considered to be medical problem also. Many adult males occasionally experience some difficulty with their penis becoming hard or staying firm, which is normal. Sex provides two detours-procreation and recreation. As the present day society is opened up, people now a days use sex more as recreation.

HISTORY: Temples like Khajuraho (In Madhya Pradesh) and Konarak (In Odisha) have stone carvings of various postures of sexual act. In Vatsayana's (His real name was Malinga, Vatsayana was his gotra) book Kamasutra (First documented book in the world to deal with sex) touched some aspects of Napumsaka or impotency. Man from ancient times is always eager to improve his sexuality by various means, such as, by massaging his genital organ with various oils, fruit juices or butter, by eating various things like testes of animals, tiger bone powder or rhinoceros's horn etc. Every man dreams to be a Casanova (The famous Italian lover). 99 percent of art and dance are sex based. Films, novels, story books even religious books are full of sexuality. In Mahabharat it is described Aravan, son of Arjun, had to be sacrificed in order to ensure victory of Pandabs in Kurukshetra war. But Aravan refused to die without a taste of marriage even for a day. As no woman was willing to marry a man doomed to die, Krishna took a female form known as Mohini and became Aravan's wife and spent a night with him. When Aravan was beheaded Krishna wailed and cried uncontrollably as a widow. Sex is the greatest hunger of man only next to hunger for food. In animals and birds, there is a period of one to two months for sex known as mating season. After mating season, they do not bother for sex and engage in search of food till the next mating season comes. But man is sexual day and night throughout the year!

Anatomy and Physiology of Normal Erection: Penis has a pair of cylindrical muscles known as Corpora Cavernosa and another group of muscle fiberes, known as Corpus Spongiosum which surrounds urethra and it bulges at the end of penis to form glans penis. Relaxation of muscle fibers allows blood to rush into erectile chambers present in corpora cavernosa and valves present there prevent flow of blood into venous channels thus resulting in hardness and erection. 


\section{ORIGINAL ARTICLE}

This hardness persists until the stimulation is stopped or an ejaculation has happened. Message from brain comes due to either touching the penis, audiovisual stimuli or fantasy. This activates the spinal erection center which help in the process of erection. Detumescence of penis occurs after orgasm and ejaculation. Release of Nitric oxide (NO) in erectile chambers of Corpora cavernosa plays an important role as neurotransmitter in the erection process.

Aetiology: Impotency is of two types. Psychological and Medical. ${ }^{1}$ Psychological impotency may be due to performance anxiety, stress or various mental diseases. Psychological cause can lead to loss of masculine self-image and maniac depression.

Medical Cause: There are two forms of impotency. (A)Primary impotency (B) Secondary impotency

1. Primary Impotency: When the person has never been able to have an erection. The causes may be due to congenital structural abnormality i.e. of penis, congenital vascular abnormalities, congenital neural abnormalities or hormonal abnormalities. These things have to be thoroughly assessed.

2. Secondary Impotency: There are lots of etiological factors responsible for causing secondary impotency. About $40 \%$ of males suffer from E.D. sometime in their life. According to one estimate $10 \%$ of males in the age group of 40-70 years have impotency. ${ }^{2}$ in recent years there is a decline of spermatozoa count in men worldwide which is a concern to scientists.

Age: E. D. is four times more common in persons of 60 s than persons of 30 s or 40 s. Potency decreases with ageing after 40 years.

Diabetes and C.V.D: E. D. can be early symptom of a significant number of diseases like Diabetes and Cardio vascular diseases.3,4 In Diabetes mellitus there is vascular, neurogenic and endothelial dysfunction. More than 50\% men develop impotency within 10 years of diagnosis of Diabetes. Cardiovascular risk factors like obesity, hypertension, atherosclerosis, hyperlipidaemia, antihypertensive drugs, such as, beta blockers, ACE inhibiters may be responsible for E.D. Smoking, alcoholism, sedentary life, lack of exercise, food habits also are contributory factors.

Drug: Amphetamine, Digoxin, Clonidine, Cemetidine, Opiates, Antidepressants, Arsenic etc.

Diseases: Spinal cord injury, Pelvic surgery, Radiation therapy, Thyroid diseases, Hormonal deficiencies like Testosterone, Pituitary, Hypogonadism, Hyperprolactinaemia, Peyronie's disease, Multiple sclerosis etc.

Other Factors: Bicycling, Smoking, Alcoholism (Enhances mood but takes away performance) poor health.

Investigation: Blood: Testosterone level, Prolactin level, Leutenizing hormone level, test to know sensation in penis, Nocturnal penile tumescence test (NPT) (Normally a healthy person has 5-6 erections during sleep, specially during Rapid Eye Movement period), Duplex ultrasound, Cavernosography and Magnetic resonance angiography.

Treatment: Sexual desire (Libido), Erectile function, Testosterone level diminish with age.

General: Good healthy diet, exercise, Avoidance of smoking or eating' gutka' (Nicotine). Avoid excessive use of alcohol. 


\section{ORIGINAL ARTICLE}

Medical: Modern sex therapy owes much to the contribution of Masters and Johnson:

1. Injection of drugs to corpora cavernosa of penis-Drugs like Papaverin, Prostaglandin E1, Phentolamine etc.

2. PDE 5 inhibitors (Phosphodiesterase inhibitors) revolutionalised the treatment of impotency. Drugs like Sildenafil (Viagra), Vardenafil (Levitra), Taldenafil (Cialis) are available in market. ${ }^{5}$ One of the advertisents of Viagra says "Take a pill and be like a Bill" (Bill Clinton).

3. A topical cream combining Alprostadil with DDAP marketed as Vitaros is available in some countries. ${ }^{6}$

4. Vaccum pump: It has three components- a chamber, a pump and a constriction elastic ring. Vaccum is applied to penis for a few minutes causing swelling and rigidity of penis (Tumescence) then an elastic ring is applied to the base of penis to sustain erection.

5. Pornographic literatures and films (Blue Film) act like aphrodisiac in some selected married couples as observed by the author.

6. Various herbal medicines are available in market whose efficiency are not scientifically proved.

7. Surgery: Penile prosthesis is often the last resort when other measures failed. Penile implants may be either inflatable or rigid (Rod).

\section{REFERENCES:}

1. Carson C, McMohan CG: Fast facts - Erectile Dysfunction, Health press .Fourth Edition 2008; 1542.

2. Chew KK, Earle CM, stuckey BG et al. Erectile Dysfunction in general medicine practice: Prevalence and clinical correlates. Int J Impot Res 2000; 12:41-5.

3. Vinik A, Richardson D. Erectile dysfunction in diabetes. Diabetes Rev 1998; 6:16-33.

4. Giuliano FA, Leriche A, Jaudinot EO et al. Prevalence of Erectile dysfunction among 7689 patients with diabetes or hypertension, or both. Urology 2004; 64:1196-201.

5. Sussman DO. Pharmacokinetics, pharmacodynamics and efficacy of phosphodiesterase type 5 inhibitors. J Am Osteopath Assoc 2004; 104(3 suppl. 4): S11-5.

6. Fisher W, Boroditsky R, Morris B. The 2002 Canadian Contraception study: part 1. J Obstet Gynaecol Can 2004; 26: 646-56.

\section{AUTHORS:}

1. P. K. Dash

\section{PARTICULARS OF CONTRIBUTORS:}

1. Professor, Department of Dermatology, Rama Medical College, Kanpur, Uttar Pradesh.

FINANCIAL OR OTHER COMPETING INTERESTS: None
NAME ADDRESS EMAIL ID OF THE CORRESPONDING AUTHOR:

Dr. P. K. Dash,

Professor, Department of Dermatology, Rama Medical College, Mandhana, Kanpur-209217, Uttar Pradesh.

E-mail: dr_pkdash@rediffmail.com

Date of Submission: 09/10/2015.

Date of Peer Review: 10/10/2015.

Date of Acceptance: 19/10/2015.

Date of Publishing: 27/10/2015. 